\title{
Alguns métodos para resolução consensual de conflitos (autocompositivos e heterocompositivos)
}

\author{
Some methods for consensual conflict resolution (self-composition and hetero- \\ composition)
}

Wilson Pereira de Assis ${ }^{1 *}$, Bruno Smolarek Dias ${ }^{1}$

\section{RESUMO}

Neste artigo discorro sobre alguns métodos de resolução consensual de conflitos, interação social, conflito e cooperação visando melhor compreender sua conceituação e, por consequência, possibilitar uma melhor compreensão sobre a importância desses métodos de resolução consensual de conflito. Apresento um conceito mais amplo de conflito e faço uma relação entre conflito, cooperação e alguns métodos de resolução consensual de conflitos (autocompositivos e heterocompositivos).

Palavras-chave: Métodos de resolução consensual de conflitos; Interação social; Conflito e Cooperação.

\section{ABSTRACT}

This article discusses the methods of consensual conflict resolution, social interaction, conflict and cooperation in order to better understand their conceptualization and, consequently, enable a better understanding of the importance of these methods of consensual conflict resolution. I present a broader concept of conflict and make a relationship between conflict, cooperation and some methods of consensual conflict resolution (selfcomposition and hetero-composition).

Keywords: Consensual conflict resolution methods; Social interaction; Conflict and Cooperation.

\section{INTRODUÇÃO}

Este artigo abordará alguns os métodos de resolução consensual de conflitos, antes, contudo, discorrer-se-á sobre interação social, conflito e cooperação com o propósito de auxiliar na compreensão do que seja conflito propriamente dito para que, com isso, entendase a importância da utilização desses métodos de resolução.

De antemão, sem qualquer exagero, pode-se afirmar que o conflito e a cooperação fazem parte do dia a dia do ser humano e isso retrata o que é interação social. Caso a cooperação prevalecesse em todas as relações sociais não haveria divergências de ideias e nem conflitos de interesses.

\footnotetext{
1* Universidade Paranaense - UNIPAR - campus Umuarama (PR).
}

*E-mail: wilson.assis@edu.unipar.br 
Aparentemente, a predominância absoluta da cooperação seria o modelo ideal de relação social, contudo, como dito alhures, o conflito faz parte de nosso dia a dia e isso nem sempre pode ser visto como ruim, conforme mais adiante será abordado.

O conflito, por sua vez, pode ter maior ou menor relevância (pessoal e/ou jurídica) a depender dos ânimos e objetivos dos envolvidos, bem como do resultado advindo desse conflito.

Moscovici (1997, p. 146) explica que:

A partir de divergências de percepções e ideias, as pessoas se colocam em posições antagônicas, caracterizando uma situação de conflito. Desde as mais leves até as mais profundas, as situações de conflitos são componentes inevitáveis e necessárias a vida grupal.

\section{Continua Moscovici (1997, p.146-147):}

A natureza das divergências está relacionada aos fatos que cada pessoa considera, os quais decorrem de informações diferentes, definições diversas do problema ou situação, aceitação ou rejeição de dados relevantes etc. Relaciona-se também com os objetivos, vistos como desejáveis ou indesejáveis, trazendo discordâncias quanto a metas. Conseqüentemente, surgem divergências quanto a procedimentos, estratégias, melhor maneira de alcançar um objetivo comum, ou seja, nos métodos. Finalmente, concorrem para as diferenças individuais os valores, considerações morais quanto ao exercício do poder, concepções sobre justiça, equidade, julgamento ético do tipo os fins justificam os meios, etc.

Ocorre que o conceito de conflito é muito amplo e não se limita às definições apresentadas, razão disso, seguem adiante algumas outras definições sobre o que é conflito, a saber:

Chiavenato (2003, p.305):

Conflito significa a existência de idéias, sentimentos, atitudes ou interesses antagônicos e colidentes que podem se chocar. Sempre que se fala em acordo, aprovação, coordenação, resolução, unidade, consentimento, consistência, harmonia, deve-se lembrar que essas palavras pressupõem a existência ou a iminência de seus opostos, como desacordo, desaprovação, dissensão, desentendimento, incongruência, discordância, inconsistência, oposição - o que significa conflito.

Moore (1998. p.5) escreveu:

Todas as sociedades, comunidades, organizações e relacionamentos interpessoais experimentam conflitos em um ou outro momento no processo diário de interação. O conflito não é necessariamente ruim, anormal ou disfuncional, é um fato da vida.

[...]

Entretanto, o conflito pode ir além do comportamento competitivo e adquirir o propósito adicional de infligir dano físico ou psicológico a um 
oponente, até mesmo a ponto de destruí-lo. É aí que a dinâmica negativa e prejudicial do conflito atinge seu custo máximo.

Zaparolli, citado por Semíramis, diz que $O$ conflito é um desacordo e, em geral, as pessoas entram em conflito por divergência (incompatibilidade) de valores, necessidades, opiniões e desejos de uma ou de ambas as partes.

Vezzulla, parafraseado por Semíramis, escreveu que $O$ conflito consiste em querer assumir posições que entram em oposição aos desejos do outro, que envolve uma luta pelo poder e que sua expressão pode ser explícita ou oculta atrás de uma posição ou discurso encobridor.

Em que pese o conflito sempre gerar a ideia de beligerância, nem sempre esse embate tem conotação negativa, pelo contrário, também é possível encontrar traços positivos. Isso é pregado por Moscovici (1997, p. 146), quando escreveu:

De um ponto de vista mais amplo, o conflito tem muitas funções positivas. Ele previne a estagnação decorrente do equilíbrio constante da concordância, estimula o interesse e a curiosidade pelo desafio da oposição, descobre os problemas e demanda sua resolução. Funciona, verdadeiramente, como raiz de mudanças pessoais, grupais e sociais.

No mesmo sentido, leciona Robbins, ao fazer a distinção entre conflitos disfuncionais destrutivos (atrapalham o desempenho do grupo) e os funcionais (melhoram o desempenho de um grupo ou de uma relação).

Veja-se o que escreveu Robbins (2005, p. 327):

[...] alguns conflitos apoiam os objetivos do grupo e melhoram seu desempenho; estes são os conflitos funcionais, formas construtivas de conflito. Por outro lado, existem conflitos que atrapalham o desempenho do grupo; são formas destrutivas ou disfuncionais de conflito. O que diferencia um conflito funcional de um disfuncional? As evidências indicam que precisamos observar o tipo de conflito. Existem três tipos de conflito: de tarefa, de relacionamento e de processo. O conflito de tarefa está relacionado ao conteúdo e aos objetivos do trabalho. O conflito de relacionamento se refere às relações interpessoais. $\mathrm{O}$ conflito de processo relaciona-se à maneira como o trabalho é realizado. Os estudos demonstram que os conflitos de relacionamento são quase sempre disfuncionais. Por quê? Aparentemente, o atrito e as hostilidades interpessoais inerentes aos conflitos de relacionamento aumentam os choques de personalidades e reduzem a compreensão mútua, o que impede a realização das tarefas organizacionais. Por outro lado, níveis reduzidos de conflito de processo e níveis de baixos a moderados de conflito de tarefa são funcionais. Para que o conflito de processo seja produtivo, seu nível tem de ser baixo. A discussão intensa sobre quem deve fazer o quê tornase disfuncional quando gera incertezas sobre os papéis de cada um, aumenta o tempo de realização das tarefas e leva os membros a trabalhar com propósitos difusos. Um nível baixo a moderado de conflito de tarefa 
demonstra consistentemente um efeito positivo no desempenho do grupo por estimular a discussão de idéias que ajudam o trabalho em equipe.

E, não bastasse a preocupação com o conflito em si, não menos importante, tem-se a resolução desse conflito que, dependendo da forma, pode não resolver apropriadamente a divergência existente, permanecendo ou emergindo insatisfação pessoal para os envolvidos.

Em sentido similar, Cintra (2000, p.20) leciona [...] o conflito não solucionado tem por consequência a insatisfação que desencadeia a instabilidade social sendo fator de sofrimento e infelicidade, que deve ser necessariamente superado.

É o comportamento dos envolvidos que ditará e atribuirá a dimensão desse conflito e, por consequência, a forma de sua eventual resolução. $\mathrm{O}$ ato consciente ou inconsciente de querer que prevaleça o anseio pessoal sobre o desejo alheio deve ser controlado para que o conflito não se sobreponha à pacificação.

Nesse sentido, Weber (1999, p.33) escreveu:

Todas as qualidades imagináveis de uma pessoa e todas as espécies de constelações possíveis podem pôr alguém em condições de impor a sua vontade numa situação dada. Por isso, o conceito sociológico de "dominação" deve ser mais preciso e só pode significar a probabilidade de encontrar obediência a uma ordem.

Ainda segundo Weber (1999, p.14):

A ação social (incluindo omissão ou tolerância) orienta-se pelo comportamento de outros, seja este passado, presente ou esperado como futuro (vingança por ataques anteriores, defesa contra-ataques presentes ou medidas de defesa para enfrentar ataques futuros). Os "outros" podem ser indivíduos e conhecidos ou uma multiplicidade indeterminada de pessoas completamente desconhecidas.

Boudon (1995, p. 28) ensina:

O primeiro princípio fundamental da sociologia da ação consiste em levar a sério o fato de que todo fenômeno social, qualquer que seja, é sempre o resultado de ações, de atitudes, de convicções, e em geral de comportamentos individuais. O segundo princípio, que completa o primeiro, afirma que o sociólogo que pretende explicar um fenômeno social deve procurar o sentido dos comportamentos individuais que estão em sua origem.

Para que o conflito não tome dimensão maior do que realmente é, deverá haver um equilíbrio entre os interesses conflitantes para que o bom senso entre os evolvidos prevaleça e seja adotado a melhor solução para o caso concreto.

Lewis A. Coser, parafraseado por Andrade (2014, p. 24) entende: 
O cientista social não pode se deslumbrar com um equilíbrio temporário deve, antes, sensibilizar-se à probabilidade de que onde existe conflito e divisão também haverá forças pressionando para o estabelecimento de novos tipos de equilíbrio, devendo prestar atenção às forças conflitantes que levaram ao seu estabelecimento.

Haverá conflito se houver interação social negativa, ou seja, as partes envolvidas interagem sobre determinado assunto que não finda em consenso, vez que as ideias ou mesmo os objetivos são antagônicos, há subjetividade. Percebe-se, portanto, que conflito colide com a cooperação.

Bobbio, Matteucci e Pasquino (1998, p. 225) entendem que [...] qualquer grupo social, qualquer sociedade histórica pode ser definida em qualquer momento de acordo com as formas de Conflito e de cooperação entre os diversos atores que nela surgem.

Como forma de se evitar e/ou amenizar um conflito, faz-se necessário apaziguar os ânimos e/ou equilibrar a vontade dos envolvidos.

Para Dinamarco, Cintra e Grinover (2011, p. 25) é necessário harmonizar as relações sociais intersubjetivas, a fim de ensejar a máxima realização dos valores humanos com o mínimo de sacrifício e desgaste.

Ainda, importa destacar que existem algumas classificações e causas para o conflito, mas, no particular, não é objetivo deste estudo esgotar todo o assunto, mas tão somente definir de forma sucinta e objetiva para uma melhor compreensão acerca da utilização dos métodos de resolução consensual de conflito.

Conquanto, para o presente estudo, é importante destacar os conflitos interpessoais (especialmente) e conflito intrapessoal. Neste, o conflito existe na mente da própria pessoal, há conflito com si própria, há uma espécie de conflito interno. Naquele, o conflito existe entre duas ou mais pessoas, há conflito de interesses, mas não necessariamente há uma disputa.

Conforme Santana (2019), conflito interpessoal é aquele que surge de uma divergência entre dois ou mais indivíduos. Leme (2004) acrescenta:

Os conflitos interpessoais, aqui entendidos como situações de interação social de confronto, desacordo, frustração, etc., e que são, portanto, desencadeadoras de afeto negativo, podem ser resolvidos de maneira violenta ou pacífica, dependendo, justamente, dos recursos cognitivos e afetivos dos envolvidos, e dos contextos sociais em que ocorrem. 
O conflito existe, por isso é necessário, consoante Fiorelli; Fiorelli; Malhadas Junior (2008, p. 6) identificá-lo, compreendê-lo, interpretá-lo e utilizá-lo para benefício de cada indivíduo, das famílias, dos grupos sociais, das organizações e, enfim, da sociedade.

Nota-se, portanto, que o conflito está diretamente ligado às relações humanas e, nalguns casos, há divergências lúcidas de ideias, noutros a divergência evidencia mera vaidade. Noutras palavras, o conflito nada mais é que a recusa em aceitar a cooperação.

\section{BREVES CONSIDERAÇÕES SOBRE MÉTODOS DE RESOLUÇÃO} CONSENSUAL DE CONFLITOS

Quando se fala em métodos de resolução consensual de conflitos é necessário fazer a devida classificação, qual seja a autocomposição e a heterocomposição. Nesta há o Estado exercendo a jurisdição, bem como a arbitragem de caráter privado, na qual as partes em discórdia escolhem um terceiro (árbitro) pata tentar solucionar a pendenga.

A escolha desse terceiro fica a critério das partes que, por sua vez, ficam vinculados à decisão determinada pelo árbitro. $\mathrm{Na}$ autocomposição às partes envolvidas chegam espontaneamente a um acordo. Todavia, não há obste para que terceiro(s) contribua(m) para o fim do conflito, mas sem imposição de decisão.

Esse(s) terceiro(s) exerce(m) função de facilitador(es), visa estreitar a comunicação entre os confrontantes instigando-os ao acordo, mas a decisão final sempre compete às partes. O objetivo é facilitar o alcance de uma solução entre os conflitantes.

Certo é que tanto a autocomposição como a heterocomposição são meios de acesso à Justiça e com a vigência da Lei 13.105 de 16 de março de 2015 (Código de Processo Civil, ou simplesmente CPC) os meios alternativos de solução de conflitos passaram a ter maior evidência, já que contribuem para diminuir a quantidade de processos e, por consequência, ajudam a desafogar o Poder Judiciário das intermináveis demandas.

Por conta disso, e em busca da pacificação social célere, o Conselho Nacional de Justiça (CNJ), por meio da Resolução 125/2010, apresentou a conciliação e a mediação como Política Judiciária Nacional, porém sem restringir, por óbvio, a aplicação de outros métodos consensuais de solução de conflitos, corroborado pela vigente norma processual civil, artigo 175, a seguir transcrito:

Art. 175. As disposições desta Seção não excluem outras formas de conciliação e mediação extrajudiciais vinculadas a órgãos institucionais ou 
realizadas por intermédio de profissionais independentes, que poderão ser regulamentadas por lei específica.

Parágrafo único. Os dispositivos desta Seção aplicam-se, no que couber, às câmaras privadas de conciliação e mediação.

Com essa apresentação o CNJ uniformizou os métodos consensuais de solução de conflitos também objetivando evitar a desigualdade de orientação e práticas.

Sobre a questão, Heringer (2012, p. 42), entende:

A proposta de criação de um serviço com tais características, antes de ser uma opção, corrobora o sentido de "falência" da natureza originária do Poder Judiciário, pois, contrario senso, buscando a modernização das leis processuais, encurtando os ritos dos processos judiciais, limitando o número e espécie de recursos existentes e que muitas vezes são protelatórios, vinculando as decisões superiores aos precedentes, melhorando as atuais estruturas e gestão dos Tribunais e, principalmente, se a União e seus entes deixassem de serem os maiores demandantes e recorrentes da justiça, em fim havendo interesse político em mudanças realmente pragmáticas neste sentido, ao ponto do Poder Judiciário poder dar as respostas que a sociedade tanto almeja quanto ao seu aspecto mais limitador - a morosidade dos julgamentos, não se falaria em novas formas ou novos serviços de atuação judiciária.

E continua:

Esta percepção é a que encontramos na política pública judiciária promovida pela resolução n. 125/2010 do CNJ. Como antes afirmado neste estudo é salutar e louvável a iniciativa do Estado/Judiciário em promover uma estrutura a implantação da cultura no país para o tratamento do conflito de interesse por meio da autocomposição, contudo, a sistematização dos modelos sugeridos deveriam ser pensados como forma subsidiária ao modelo de atividades originárias do Judiciário.

Embora muitos acreditam que é responsabilidade exclusiva do Poder Judiciário a demora na tramitação de processos, tenho que isso não é verdade absoluta, tanto que essa culpa pode ser dividida com o próprio jurisdicionado.

Isso, pois, é alta a quantidade de processos que são distribuídos e as partes envolvidas acabam por conciliar e/ou reconciliar durante a tramitação de seus respectivos processos.

Ainda que tais processos não cheguem a esgotar todo o percurso processual em primeiro grau, é fato que a simples distribuição já movimenta a estrutura Judiciária, ou seja, já movimenta a máquina judiciária.

É lógico que a prestação jurisdicional ocorre por meio de sentença de mérito num processo litigioso ou num processo/procedimento de jurisdição voluntária. Nesta hipótese, há, conforme o caso, homologação judicial acerca do pactuado. 
Todavia, a sentença meritória num processo contencioso pode não entregar uma efetiva prestação jurisdicional, já que a vontade dos postulantes pode não restar integralmente satisfeita.

Contrário disso, a aplicação de certos métodos de resolução de conflitos pode chegar mais perto da efetiva prestação jurisdicional, haja vista que a vontade dos então litigantes prevalecerá, competindo ao julgador homologar o pacto firmado, conforme o caso.

No caso de procedimento de jurisdição voluntária, conforme preconiza o parágrafo único do artigo 723 do Código de Processo Civil, o juiz não é obrigado a observar critério de legalidade estrita, podendo adotar em cada caso a solução que considerar mais conveniente ou oportuna.

Isso proporciona às partes no processo resolverem suas controvérsias com menor rigor, maior celeridade e com menos intervenção estatal, via Poder Judiciário, verdadeiro sentido da existência/criação dos meios alternativos de resolução de conflitos.

Pensando nisso, o legislador, por meio dos artigos 319, VII, 694 e 695 do Código de Processo Civil, dita a obrigatoriedade do agendamento de audiência/sessão de conciliação/mediação.

O primeiro diploma citado reza sobre os requisitos da petição inicial e impõe a indicação sobre a opção do autor pela realização ou não de audiência de conciliação ou de mediação.

O artigo 694 dita que Nas ações de família, todos os esforços serão empreendidos para a solução consensual da controvérsia, devendo o juiz dispor do auxílio de profissionais de outras áreas de conhecimento para a mediação e conciliação.

Por fim, o artigo 695 determina que Recebida a petição inicial e, se for o caso, tomadas as providências referentes à tutela provisória, o juiz ordenará a citação do réu para comparecer à audiência de mediação e conciliação, observado o disposto no art. 694.

Vale lembrar que, embora conciliação e mediação sejam parecidas, há diferença significativa entre elas. Na conciliação, em princípio, e diverso do que ocorre na mediação, não há relacionamento entre as partes, o terceiro, denominado conciliador, pode conduzir a audiência com maior liberdade e menor formalismo.

$\mathrm{Na}$ conciliação, o conciliador pode sugerir propostas de acordos, discutir pontos positivos e negativos, dar opiniões e ideias, além de poder interferir diretamente no ato e aconselhar, sem, contudo, adentrar profundamente no mérito da divergência.

Acerca dessa situação, Vezzulla (2001, p. 43) diz: 
A conciliação como técnica é de grande utilidade nos problemas que não envolvem relacionamento entre as partes, o que permite trabalhar sobre a apresentação superficial (verdade formal ou posição) para alcançar uma solução de compromisso sem repercussão especial no futuro de suas vidas.

Contrário disso, na mediação, o terceiro envolvido, denominado de mediador, não pode sugerir propostas, não pode dar ideias, não pode adentrar diretamente no mérito do feito e sequer pode fazer uso e/ou pronunciar algumas palavras, a exemplo de "conflito" e "briga".

Em que pese isso, é fato e hialino de que o conflito existe, seja de menor ou de maior complexidade. Não diferente disso, Muller (2007, p. 18-20), escreveu que o homem é essencialmente um ser relacional e, por isso, o conflito é elemento estrutural de toda vida social.

Repostando-se à mediação, o mediador visa mediar e exteriorizar a vontade das partes, fazendo com que as próprias partes cheguem a um denominador comum e ponham fim na desavença. Em resumo, o mediador tentar reestabelecer o diálogo entre às partes.

Sobre questão similar, Costa (2014, p. 97), escreveu:

[...], para além de mera via alternativa para o desafogo do Poder Judiciário, a solução extrajudicial de conflitos revela-se como instrumento que vivifica os processos de educação em direitos e difusão da cidadania. Afinal, as dinâmicas de auto composição do litígio são eficazes em promover não só a inserção, como também o engajamento participativo e responsável do sujeito na busca pela solução do litígio em que se veja envolvido, ainda que involuntariamente. Destaca-se, nesse sentido, o papel essencial dos processos de conciliação, mediação entre outros de cunho restaurativo, nos quais não incluímos a arbitragem que, além de ter feição empresarial, acaba por transferir a terceiro - que não o Juiz, mas que também não as partes - o poder decisório.

Acima, teceu-se superficialmente alguns comentários atinentes aos métodos de resolução consensual de conflitos, com um singelo destaque para a conciliação e mediação via judicial.

Doravante algumas questões mais peculiares serão abordadas.

\section{MÉTODOS DE AUTOCOMPOSIÇÃO}

A autocomposição é forma clássica e originária de resolução de conflitos, existe desde os tempos primitivos e opera por três formas, a conciliação, mediação e negociação. 
Com o advento da Constituição Cidadã (CF/1988), a autocomposição não mais se limita ao direito privado, tanto que alcançou o Direito Penal o que, entretanto, não é objeto deste trabalho.

$\mathrm{Na}$ autocomposição, as partes, ou pelo menos uma delas, renuncia integral ou parcialmente à pretensão inicial para que haja, ainda que aparentemente, satisfação com o fim do conflito pelo modo e forma adotados pelas partes.

Cintra, Grinover e Dinamarco (2012, p. 29) afirmam que as formas de autocomposição acerca de direitos disponíveis são três, a saber: a desistência, que se refere a renúncia da pretensão; a submissão, que se refere a renúncia à resistência das partes; e transação, retratada pela concessão recíproca.

Calmon (2007, p.142) diz que:

Se, por um lado, denomina-se autocomposição judicial a solução do conflito praticada pelas próprias partes envolvidas quando há posterior homologação judicial, entende-se por conciliação a atividade desenvolvida para incentivar, facilitar e auxiliar a essas mesmas partes a se autocomporem, adotando, porém, metodologia que permite a apresentação de proposição por parte do conciliador, preferindo-se, ainda, utilizar este vocábulo exclusivamente quando esta atividade é praticada diretamente pelo juiz ou por pessoa que faça parte da estrutura judiciária especificamente destinada a este fim. (Destacado).

Hialino, porquanto, de que a autocomposição pode se resumir à prevenção ou mesmo à solução do conflito, que se opera por meio de decisão livre e consensual dos então confrontantes.

É unilateral a iniciativa para pôr fim a pendenga quando parte de um dos conflitantes e bilateral quando essa iniciativa parte de pelo menos dois dos envolvidos, ou seja, há aquiescência mútua sobre a resolução do conflito.

O fim da pendência via decisão unilateral se opera, como dito algures, pela desistência, submissão e pela transação. Contrário disso, o fim da desavença via decisão bilateral se opera por meio de uma decisão impositiva, haja vista que um terceiro decidirá o caso.

Embora o conflito faça parte de nosso dia a dia, as interações sociais tornam-se impraticáveis se não houver acordo de vontades para dirimirem as pendências que ocorrem em nosso cotidiano.

Não havendo esse essencial acordo de vontades para a pacificação social acontecer, a questão deve ser judicializada, competindo daí, ao Estado decidir pelas partes, o que, nem sempre, trará a satisfação integral aos envolvidos. 
É certo que o acordo de vontades também não é garantia de que haverá uma integral satisfação, porém, o efeito psicológico que o acordo causa às partes é muito melhor e mais positivo de que o efeito causado por uma decisão impositiva.

Por fim, conforme ensina Cambi (2020, p. 639), o atual códex processual civil estimula a solução extrajudicial das controvérsias, ao afirmar que o instrumento de transação referendado pelos advogados dos transatores é título executivo extrajudicial (art. 784, inc. IV, NCPC), extensivos aos documentos referendados pelo Ministério Público, pela Defensoria Pública e Advocacia Pública.

\section{CONCILIAÇÃO}

Como já exposto, a conciliação - em especial a extrajudicial - e a mediação se assemelham em muito, inclusive são métodos autocompositivo que dependem de um terceiro, conciliador ou mediador respectivamente, para a realização do ato (conciliação/mediação) visando a resolução do conflito.

Esse terceiro deve ser neutro, imparcial, não podendo fazer qualquer imposição e/ou forçar uma composição entre as partes, pois, na conciliação esse terceiro atua como um facilitador da decisão que será adotada pelas partes, na esperança de que essa decisão resulte em acordo e ponha fim à pendenga.

Nos termos do Código de Processo Civil, art. 165, § $2^{\circ}$, o conciliador atuará preferencialmente nos casos em que não houver vínculo anterior entre as partes. Vale observar que o instituto da conciliação não foi criado com o atual Código de Processo Civil, em vigor desde 15.03.2016, mas é fato que teve maior visibilidade e aplicação por conta do referido código, pelo menos quando se refere à conciliação judicial.

Um exemplo do instituto conciliação anterior ao atual Código de Processo Civil encontra-se na Lei 9.099 de 26.09.1995, em vigor desde 27.09.1995, que instituiu os Juizados Especiais, observando ao processo, sempre que possível, à conciliação, inclusive ditando obrigatoriedade de, tanto ao juiz leigo como ao togado, fazer esclarecimentos às partes sobre a vantagem da conciliação.

Em resumo, isso está inserto nos artigos $2^{\circ}, 21$ e 22 da referendada Lei, a seguir transcritos:

Art. $2^{\circ} \mathrm{O}$ processo orientar-se-á pelos critérios da oralidade, simplicidade, informalidade, economia processual e celeridade, buscando, sempre que possível, a conciliação ou a transação. 
$[\ldots]$

Art. 21. Aberta a sessão, o Juiz togado ou leigo esclarecerá as partes presentes sobre as vantagens da conciliação, mostrando-lhes os riscos e as conseqüências do litígio, especialmente quanto ao disposto no $\S 3^{\circ}$ do art. $3^{\circ}$ desta Lei.

Art. 22. A conciliação será conduzida pelo Juiz togado ou leigo ou por conciliador sob sua orientação.

Mas não é só, antes mesmo da entrada em vigor da Lei 9.099/95, a Ordem dos Advogados do Brasil, por meio do Código de Ética e Disciplina, em vigor desde 01.03.1995, art. $2^{\circ}$, Parágrafo único, VI, regrou como sendo dever do advogado estimular a conciliação entre os litigantes, prevenindo, sempre que possível, a instauração de litígios.

Entretanto, as matérias que podem ser objetos de conciliação, e que são objetos deste trabalho, estão relacionadas a direitos patrimoniais privados - cível - e nas causas relacionadas ao direito de família.

Quanto as etapas, Braga Neto (2003, p. 23) explica:

[...] a conciliação consiste no emprego de somente quatro etapas, a saber: - Abertura, onde são feitos, por intermédio do conciliador, os esclarecimentos iniciais sobre o procedimento e todas as implicações legais referentes ao alcance do acordo gerado naquela oportunidade ou de sua impossibilidade; - Esclarecimentos das partes sobre suas ações, atitudes e iniciativas que acabaram por fazer nascer o conflito. Momento de vital importância no procedimento, pois é nele que se manifestam as posições de cada uma das partes. $\mathrm{O}$ conciliador, por seu turno, deverá identificar os pontos convergentes e divergentes da controvérsia, mediante o desencadeamento de perguntas sobre o fato e a relação causal entre eles, bem como se fazer valer de uma escuta ativa sobre a comunicação verbal e não verbal das partes. Na sequência, encaminha-se para o estímulo à criação de opções; - Criação de opções, quer por sugestões trazidas pelo terceiro, quer por intermédio de propostas delineadas pelas partes, com o objetivo de atingir o almejado consenso pela solução, e posteriormente; $\underline{\mathrm{O} \text { acordo, }}$ sua redação e assinatura. (Destacado).

Braga Neto continua:

Aos conflitos oriundos de relações emocionais ou continuadas cabe a escolha de um processo mais profundo, de interferência sutil e adequada à complexidade do problema. Isso porque o ideal nesse tipo de conflito é que se resolva tanto o problema real quanto o problema aparente; tanto o conflito em si como a causa desse conflito. Nesse processo, é importante que se tenha oportunidade de trabalhar os interesses e necessidades das partes, bem como o futuro das mesmas, não restringindo a solução à problemática posta em discussão. (Destacado).

Conforme lecionam Farinelli e Cambi (2011, p. 288):

A eficácia da conciliação exige discussão aberta, direta e franca entre as partes. Pode acontecer antes ou depois da instauração do processo. É 
importante alternativa de aproximação e participação dos envolvidos na solução do conflito. Mas também proporciona efetivo acesso à justiça, já que sua eficácia depende do tratamento igualitário entre os contendores que decidem, em conjunto e da melhor forma, a situação conflituosa, buscando a maior harmonia e a mútua satisfação.

Na conciliação o objetivo é o acordo em si, evitando assim o prosseguimento do processo e/ou sua extinção caso o processo já tenha sido instaurado. Vasconcelos (2008, p. 79), sobre conciliação ensina:

[...] trata de procedimento adotado em complemento ao processo judicial, pelo próprio julgador ou por pessoa autorizada, a serviço daquele juízo. A segunda particularidade está no dado de que se trata de modelo focado no acordo, aproximando-se, neste aspecto, da mediação satisfativa. A terceira está na circunstância de que os mediadores não são escolhidos ou, de algum modo, submetidos a um juízo de aceitação pelas partes envolvidas, pois já estão pré-determinados naquela função. A quarta está em exercerem uma ascendência hierárquica durante as sessões, reduzindo as possibilidades do protagonismo. A quinta particularidade e que a conciliação não prevê entrevistas previas ou incidentais, em separado. Finalmente, porque os conciliadores - naquela situação de ascendência hierárquica do ambiente judicial - aconselham, advertem e induzem as partes ao acordo.

Vale dizer que induzir as partes ao acordo não significa apresentar às partes a proposta de acordo propriamente dita, mas sim instigar e demonstrar às partes de que o acordo é melhor.

É por isso que a capacitação do conciliador é fundamental, já que a experiência e a técnica adotadas farão a diferença quando da condução, explicação e convencimento das partes sobre os benefícios de um acordo.

Para Fischer; Ury; e Patton (2005):

A conciliação dos interesses, em vez das posições, funciona por dois motivos. Primeiro, porque, para cada interesse, geralmente existem diversas posições possíveis e capazes de satisfazê-lo. [...] Quando se examinam realmente os interesses motivacionais por trás das posições opostas, frequentemente se descobre uma posição alternativa que atende não apenas aos interesses de uma das partes como também da outra.

Heringer (2012, p. 42-43):

A conciliação e mediação são instrumentos efetivos de pacificação social, solução e prevenção de litígios, pois, na prática evitam a materialização do conflito ou 43 cessam um conflito existente. São eficazes quanto ao encurtamento do tempo de duração do processo judicial proporcionando no seu curso os meios para a solução por acordo entre as partes, colocando termo ao litígio mais rapidamente do que levaria no seu curso normal, o que por si só é positivo, mas, sempre no bojo de um processo judicial. 
Nota-se, portanto, que a conciliação para ser exitosa também depende da capacitação do conciliador.

\section{MEDIAÇÃO}

A mediação pode ser judicial ou extrajudicial e tem como regramento principal a Lei 13.140, de 26 de junho de 2015. Na mediação extrajudicial as partes buscam espontaneamente um terceiro (mediador) para mediar a situação e tentar resolver o caso, pondo fim no conflito. Na judicial, por sua vez, se opera no âmbito do Poder Judiciário, sendo o mediador pessoa indicada pelo Tribunal.

Na mediação judicial caso o conflito não finde, o processo seguirá seu curso normal. Como depende dos conflitantes para findar a pendenga, a mediação tem natureza autocompositiva, na qual os confrontantes têm um terceiro (mediador) imparcial ou um grupo de pessoas para mediar a causa em busca de uma composição.

Em que pese isso, esse terceiro deve se comportar de forma inerte no tocante aos termos de eventual acordo. O mediador não pode sugerir acordo ou mesmo discutir eventuais propostas apresentadas pelas partes e, nos termos do artigo 165, $\S 3^{\circ}$, do Código de Processo Civil, atuará preferencialmente nos casos em que houver vínculo anterior entre as partes.

De acordo com Souza (2013, p. 212):

[...], quanto maior o grau de envolvimento entre as partes, mais adequada parece ser a perspectiva da mediação transformativa. Nesta, o mediador privilegia a atuação das partes na evolução do diálogo e na construção da solução, sem sugerir comportamentos específicos, mas apenas buscando ressaltar sutilmente a necessidade de cada parte assumir seu poder e responsabilidade pessoal, bem como de se sentir ouvida e reconhecida pela outra parte.

Deve, de fato, mediar a situação e deixar às partes decidirem livremente sobre o caso. A mediação extrajudicial acontece sem interferência judicial, por um mediador ou câmara privada, e o mediador não precisa ter qualquer graduação. A mediação extrajudicial é, em princípio, mais célere de que a mediação judicial.

A mediação judicial acontece junto ao Poder Judiciário e o mediador precisa ter formação superior em qualquer área, a pelo menos dois anos e que tenha sido capacitada para exercer a mediação em instituição ou escola reconhecida pela Escola Nacional de Formação e Aperfeiçoamento de Magistrados - ENFAM ou pelos tribunais (art. 11 da Lei 
em referência). Ainda, a mediação judicial acontecerá nos Centros Judiciários de Solução Consensual de Conflitos (CEJUSC).

Feito esses esclarecimentos, colacionam-se alguns conceitos sobre medição, veja-se: Nas palavras de Braga Neto (1999, p. 93):

Mediação é uma técnica não-adversarial de resolução de conflitos, por intermédio da qual duas ou mais pessoas (físicas, jurídicas, públicas etc.) recorrem a um especialista neutro, capacitado, que realiza reuniões conjuntas e/ou separadas, com o intuito de estimulá-las a obter uma solução consensual e satisfatória, salvaguardando o bom relacionamento entre elas.

Para Fiorelli; Fiorelli; Malhadas Junior (2008, p. 58) A mediação constitui um processo de transformar antagonismos em convergências, não obrigatoriamente em concordâncias, por meio da intervenção de um terceiro escolhido pelas partes.

Embora o procedimento adotado pela mediação (judicial ou extrajudicial) seja importante e, em princípio, o melhor para o reestabelecimento da relação dos confrontantes (em casos de família, por exemplo), de nada adiantará se a vontade dos conflitantes não convergir.

Braga Neto (1999, p. 94) catequiza:

[...] a iniciativa possibilitará que os envolvidos passem a encarar de forma positiva o conflito, que é inevitável, não o negando e se utilizando de subterfúgios para fugir do mesmo. Essa mudança de visão permitirá que os litigantes possam vislumbrar caminhos a futuro que permitirão estabelecer um novo relacionamento, a fim de alcançar uma boa convivência futura.

Deixar de lado a vaidade em prol do bem comum e sem a preocupação cultural a respeito de quem perde ou de quem ganha é fundamental, e isso contribui diretamente para o reestabelecimento da relação entre os envolvidos na discórdia. Reestabelecer o diálogo é meta.

Schnitman (1999, p.17) aduz:

Nossa cultura privilegiou o paradigma ganhar-perder, que funciona como uma lógica determinista binária, na qual a disjunção e a simplificação limitam as opções possíveis. A discussão e o litígio - como métodos para resolver diferenças - dão origem a disputas nas quais usualmente uma parte termina ganhadora, e outra, perdedora. Essa forma de colocar as diferenças empobrece o espectro de soluções possíveis, dificulta a relação entre as pessoas envolvidas e gera custos econômicos, afetivos e relacionais.

Para Vezzulla (2001, p. 48):

O papel do mediador na sociedade é o de restabelecer a harmonia à medida que respeita, escuta e sustenta cada uma das partes envolvidas no conflito, 
levando-as assim a que elas se respeitem, se escutem e possam reafirmar o relacionamento em que ambos se reconheciam e se respeitavam.

O papel do mediador não é fácil, deve, sem adentrar no mérito do conflito, esclarecer sobre os benefícios da composição, especialmente quando a relação dos então conflitantes é continuada.

O mediador buscará a solução não apenas para o conflito, mas sim do caso em si. Não basta resolver o conflito, é imprescindível que as partes compreendam a situação vivenciada e voltem a interagirem, reconhecendo o caráter transitório do embate.

Para Mílard Zhaf Alves LehmKuhl, citado por Vasconcelos (2005, p. 82):

[...] os conflitos interpessoais devem ser vistos de forma positiva, como uma transição aprimorada, como um ciclo de reciclagem, pelo qual as pessoas estão se renovando constantemente, através da adequação pessoal com o meio coletivo em que vivem, fato este que traria uma maior satisfação social, posto que, mesmo tendo que passar pelos citados conflitos, através de sua visão não negativas destes, as pessoas compreenderiam o caráter transitório e necessários dos mesmos, vindo por fim a aceitá-los e compreendê-los, facilitando deste modo a sua resolução.

Segundo o Manual de Mediação do CNJ, citado por Ramidoff1 e Borges:

Um conflito possui um escopo muito mais amplo do que simplesmente as questões juridicamente tuteladas sobre a qual as partes estão discutindo em juízo. Distingue-se, portanto, aquilo que é trazido pelas partes ao conhecimento do Poder Judiciário daquilo que efetivamente é interesse das partes. Lide processual é, em síntese, a descrição do conflito segundo os informes da petição inicial e da contestação apresentados em juízo. Analisando apenas os limites dela, na maioria das vezes não há satisfação dos verdadeiros interesses do jurisdicionado. Em outras palavras, pode-se dizer que somente a resolução integral do conflito (lide sociológica) conduz à pacificação social; não basta resolver a lide processual - aquilo que foi trazido pelos advogados ao processo - se os verdadeiros interesses que motivaram as partes a litigar não forem identificados e resolvidos. Além do problema imediato que se apresenta, há outros fatores que pautam um conflito, tais como o relacionamento anterior das partes, as suas necessidades e interesses, o tipo de personalidade das partes envolvidas no conflito, os valores das partes e a forma como elas se comunicam. Muitos desses fatores considerados secundários por alguns operadores do direito estão, na verdade, na origem do conflito e, por isso, devem ser levados em conta na solução do problema. A mediação deve considerar aspectos emocionais durante o processo e ao mediador não caberá decidir pelas partes, mas conduzi-las a um diálogo produtivo, superando barreiras de comunicação a fim de que as partes encontrem a solução (CNJ, 2016, p. 148).

Resumindo, a mediação ocorrerá nos casos nos quais o conflito existente decorre de uma relação pré-existente entre os conflitantes e o mediador atuará como um facilitador, 
auxiliando-os, sem fazer qualquer alusão ao mérito da contenda e proporcionado aos conflitantes dialogarem e resolverem o problema sem qualquer interferência externa acerca do mérito da controvérsia.

\section{NEGOCIAÇÃO}

A negociação, meio de autocomposição, pode ser considerada como um conjunto de ações praticado para se alcançar um objetivo e, via de regra, está evidente nas relações comerciais e nas questões atinente às interações interpessoais, como exemplo, o direito de família, podendo ou não, conforme o caso, depender de homologação judicial.

No tocante ao assunto, Guilherme (2018, p. 49) escreveu:

[...] a negociação não apresenta a figura de um terceiro alheio ao conflito que atue de modo a melhor posicionar as partes. O que se tem é a incursão de um conjunto de técnicas praticadas pelas próprias partes que se obstina a remediar uma situação de crise e oferecer a melhor resposta para o caso.

Para a concretização da negociação há a necessidade de planejamento e interação bilateral tencionada para um acordo, em tese, bom para todos os envolvidos. É essencial para uma boa negociação que os envolvidos unam esforços aspirando um bem comum e, com isso, fiquem ledo com o resultado alcançado, evitando-se o litígio.

Não é forçoso afirmar que a principal diferença entre negociação para com a conciliação e a mediação se refere à obrigatoriedade de haver um terceiro imparcial, figura inexiste na negociação. Negociação que, por sua vez, existe nas diversas formas de autocomposição.

Para Mota (2014, p. 27):

Na negociação, o caso é resolvido pelas próprias partes que combinam a melhor maneira, estabelecendo parâmetros e protocolos. As partes acertam os procedimentos e o mecanismo mais apropriado e conservam ou preservam o relacionamento - a paz social. Nesse caso, não há perdedor ou vencedor. Trata-se do chamado ganha-ganha. Não há sentença; há acordo.

Ainda, a negociação pode ser classificada como distributiva e integrativa. Nesta os envolvidos se dedicam ao máximo para que ocorra uma composição. Naquela, as partes competem entre si, mesmo porque acreditam que inexistirá uma relação futura entre os negociantes.

Referente à negociação integrativa Watkins (2016, p. 22) leciona: 
As negociações do tipo integrativas ou colaborativas são determinadas por um fluxo ativo de informações, com a contínua exposição dos motivos para um negócio, a abertura de reais interesses e das restrições de cada parte com determinadas soluções. Pressupõe sejam reveladas preferências entre assuntos ou opções e a análise de capacidades e recursos adicionais que possam ser adicionados ao acordo para angariar vantagens também à contraparte. Nesse passo, busca-se opções criativas com o conhecimento obtido, de modo a atender ao máximo o interesse de ambos os lados.

Quanto a negociação distributiva, Lewicki (2014, p.17) diz que Uma negociação distributiva ou competitiva (perde-ganha) é geralmente marcada por recursos e tempo escassos, uma alta competitividade entre as partes e a ausência de perspectivas de relação futura entre os litigantes.

Lewicki (2014, p. 41) afirma que, Nesse tipo de negociação, o relacionamento e a reputação são pouco significativos, e a informação é uma moeda forte na determinação do resultado. A questão essencial nesse aspecto é, assim, o controle das informações.

Parece hialino de que a negociação é a melhor forma de resolução consensual de conflito, uma vez que as tratativas para pôr fim ao imbróglio partem de iniciativas das próprias partes, sem o intermédio de facilitador.

\section{MÉTODOS HETEROCOMPOSITIVOS}

São dois os métodos de heterocomposição; arbitragem e jurisdição. Esta refere-se ao próprio processo judicial, situação em que o Poder Judiciário decidirá pelas partes, há, portanto, uma direta intervenção Estatal, em consonância com o princípio da inafastabilidade de jurisdição.

No que concerne a arbitragem, regrada pela Lei 9.307, de 23 de setembro de 1996 e também reconhecida pelo Código de Processo Civil, Art. $3^{\circ}, \S^{\circ}$. A crasso modo, tem-se que a arbitragem é um tipo de jurisdição privada, pela qual os conflitantes pactuam por meio de convenção de arbitragem que a controvérsia será apreciada e decidida por um terceiro (árbitro).

Quanto ao tema, apresento a seguinte definição, extraído do site do Tribunal de Justiça do Distrito Federal e dos Territórios - TJDFT:

A arbitragem é regulada pela Lei 9.307/96 e depende de convenção das partes, em cláusula específica e expressa, para ser aplicada. Quando as partes optam pela arbitragem, elas afastam a via judicial e permitem que um ou mais terceiros, os árbitros, que geralmente detém vasto conhecimento da matéria em questão, decidam o conflito. Os árbitros 
atuam como juízes privados e suas decisões têm eficácia de sentença judicial e não pode ser objeto de recurso.

Essa decisão não precisa ser homologada judicialmente para que seus efeitos legais e jurídicos prevaleçam. Essa decisão também é irrecorrível. A arbitragem possui rito, técnicas e princípios próprios.

O compromisso arbitral pode ser classificado de duas formas; judicial e extrajudicial. Neste, pode ser celebrado por instrumento particular ou público. Diverso do compromisso por instrumento público, o particular deve ser assinado por duas testemunhas.

Quanto ao compromisso arbitral judicial, por sua vez, será celebrado por termo nos autos, ou seja, no processo no qual a lide é discutida.

Como o objetivo deste estudo foi discorrer sobre alguns métodos para resolução consensual de conflitos, não haverá maiores aprofundamentos quanto ao tema método de heterocompositivo da espécie jurisdição (processo).

\section{CONSIDERAÇÕES FINAIS}

Sem sombra de dúvidas o conflito faz parte de nosso cotidiano e, por conta disso, os métodos de resolução consensual de conflitos surgem como meio mais adequado para pôr fim a controvérsia, com ou sem a intervenção de terceiro.

Independentemente do método de resolução de conflito adotado pelas partes o fim almejado sempre será o mesmo, que é extirpar a controvérsia então existente.

Entretanto, para que as partes ponham termo a controvérsia não pode faltar cooperação, mesmo porque, como dito alhures, conflito e cooperação andam lado a lado, formando a interação social.

Embora seja utopia, o ideal seria que a interação social sempre fosse positiva, ou seja, inexistiria o conflito de interesses e, por consequência, a relação social também seria positiva.

\section{REFERÊNCIAS:}

\section{Livro:}

BOBBIO, Norberto; MATTEUCCI, Nicola; PASQUINO, Gianfranco. Dicionário de

Política. trad. Carmen C, Varriale et ai.; coord. trad. João Ferreira; rev.geral João Ferreira 
e Luis Guerreiro Pinto Cacais. - Brasília: Editora Universidade de Brasília, 1 la ed., 1998. V.1. p.225.

BOUDON, Raymond. Ação. In: BOUDON, Raymond (org). Tratado de Sociologia. Rio de Janeiro: Jorge Zahar Editor, 1995, p. 28.

BRAGA NETO, Adolfo. Os advogados, os conflitos e a mediação. In: OLIVEIRA, Ângela (Org.). Mediação - Método de resolução de controvérsia. São Paulo: LTR, n. 1, p. 93-101, 1999.

CALMON, Petrônio. Fundamentos da Mediação e da Conciliação. Ed. Forense. Rio de Janeiro. 2007. p. 142.

CAMBI, Eduardo. Neoconstitucionalismo \& neoprocessualismo. $3^{\text {a }}$ Ed. Editora D’PLÁCIDO, 2020, p. 639.

CINTRA, Antônio Carlos Araújo et al. Teoria Geral do Processo. 16 ed., São Paulo: Malheiros, 2000, p. 20.

CINTRA, Antônio Carlos de Araújo; GRINOVER, Ada Pellegrini;

DINAMARCO, 16. Cândido Rangel. Teoria geral do processo. 28.ed. rev. e atual. São Paulo: Malheiros, 2012, p. 29.

COSTA, Domingos Barroso; GODOY, Arion Escorsin de. Educação em direitos e Defensoria Pública. Curitiba: Juruá, 2014, p. 97.

CHIAVENATO, Idalberto. Introdução à teoria geral da administração: uma visão abrangente da moderna administração das organizações. Rio de Janeiro: ELSEVIER, 2003, p. 305.

DINAMARCO, Cândido Rangel; CINTRA, Antonio Carlos de Araújo; GRINOVER, Ada Pellegrini. Teoria geral do processo. 27. ed. São Paulo: Malheiros Ed., 2011. p.25.

FIORELLI, José Osmir; FIORELLI, Maria Rosa; MALHADAS JUNIOR, Marcos Julio Olivé. Mediação e Solução de Conflitos: Teoria e Prática. São Paulo: Atlas, 2008, p. 6.

GUILHERME, Luiz Fernando do Vale de Almeida. Manual de arbitragem e mediação: conciliação e negociação. 4. ed. São Paulo: Saraiva Educação, 2018, p. 49.

MOORE, Christopher W. O Processo de Mediação: Estratégias Práticas para a Resolução de Conflitos. Trad. Magda França Lopes. 2.ed. Porto Alegre: Artmed, 1998. p.5.

MOSCOVICI, Fela. Desenvolvimento interpessoal: Treinamento em grupo. 7. ed. rev. e ampl. Rio de Janeiro: Jose Olympio, 1997, p. 146-147.

LEWICKI, Roy; SAUNDERS, David; BARRY, Bruce. Fundamentos de Negociação. $5^{\text {a }}$ ed. Porto Alegre: AMGH, 2014, p. 17 e 41. 
MULLER, Jean-Marie. O Princípio da Não-violência. São Paulo: Palas Athena, 2007, 1820 .

SCHNITMAN, Dora Fried. Novos paradigmas em resolução de conflitos. In: SCHNITMAN, Dora Fried; LITTLEJOHN, Stephen (Org.). Novos paradigmas em mediação. Porto Alegre: ArtMed, 1999, p. 17-27.

SOUZA, Luciane Moessa de. Mediação de conflitos e o novo Código de Processo Civil. In: SPENGLER, F. M., BEDIN, G. A. (Org) Acesso à justiça, direitos humanos \& mediação [recurso eletrônico]. Curitiba: Multideia, 2013, p. 212.

VASCONCELOS, Carlos Eduardo de. Mediação de conflitos e práticas restaurativas, São Paulo, Método, 2008, p. 79.

VEZZULA, Juan Carlos. Mediação: guia para usuários e profissionais. Florianópolis: Instituto de Mediação e Arbitragem do Brasil, 2001, p.43. , Juan Carlos. Mediação: guia para usuários e profissionais. Florianópolis: Instituto de Mediação e Arbitragem do Brasil, 2001, p.48.

WATKINS, Michael. Negociação. 1 ${ }^{\text {a }}$ ed. Rio de Janeiro: Record, 2016, p. 22.

WEBER, Max. Economia e Sociedade. Brasília, DF: Editora UnB, v.2, 1999, p. 14. , Max. Economia e Sociedade. Brasília, DF: Editora UnB, v.2, 1999, p. 33.

\section{Artigo de Periódico:}

ACS. Mediação X Conciliação X Arbitragem. Disponível em: https://www.tjdft.jus.br/institucional/imprensa/campanhas-e-produtos/direito-facil/edicaosemanal/mediacao-X-conciliacao-X-arbitragem. Acesso em: 05.04.2021.

ANDRADE, Adriana Maria Amado da Costa de. A perspectiva sociológica da resolução de conflitos no estudo do comportamento frente às instituições. Disponível em: https://repositorio.ufmg.br/bitstream/1843/BUOS-

9S3JE3/1/a_perspectiva_sociol_gica_da_resolu_o_de_conflitos__adriana_amado_ppgs_ _fafich.pdf. Acessado em: 03.04.2021.

BRAGA NETO, Adolfo, Adolfo. Alguns aspectos relevantes sobre a mediação de conflitos. In: SALES, Lília Maia de Morais (Org.). Estudos sobre a mediação e a arbitragem. Rio de Janeiro - São Paulo - Fortaleza: ABC, 2003, p. 23.

BRASIL. Código de Ética e Disciplina da Ordem dos Advogados do Brasil. Disponível em: CodigoEticaDisciplinaOAB.pdf (oabes.org.br). Acesso em: 03.04.2021.

Lei 9.099, de 26 de setembro de 1995 (Dispõe sobre os Juizados Especiais Cíveis e Criminais e dá outras providências). Disponível em: L9099 (planalto.gov.br). Acesso em: 29.03.2021. 
. Lei 9.307, de 23 de setembro de 1996 (Dispoe sobre a arbitragem). Disponível em: http://www.planalto.gov.br/ccivil_03/leis/19307.htm. Acesso em 29.03.2021).

. Lei n. 13.105, de 16 de março de 2015 (Código de Processo Civil). Disponível em: http://www.planalto.gov.br/ccivil_03/_ato2015-2018/2015/lei/113105.htm. Acesso em 02.04.2021.

Lei 13.140, de 26 de junho de 2015. Disponível em: http://www.planalto.gov.br/ccivil_03/_ato2015-2018/2015/lei/113140.htm. Acesso em: 04.04.2021.

Conselho Nacional de Justiça. Resolução n 125, de 29 nov. 2010. Disponível em: resolucao_comp_125_29112010_19082019150021.pdf (cnj.jus.br). Acesso em 27.03.2021.

FARINELLI, Alisson; CAMBI, Eduardo Augusto Salomão. Conciliação e mediação no novo Código de Processo Civil (PLS 166/2010). Revista de Processo, São Paulo, v. 36, n. 194, p. 277-305, abr. 2011.

FISCHER, Roger. URY, William. PATTON, Bruce. Como chegar ao sim: A negociação de acordos sem concessões. Tradução: Vera Ribeiro \& Ana Luiza Borges. - $2^{a}$ Ed. rev. e ampl. - Rio de Janeiro: Imago, 2005. Disponível

em:https://edisciplinas.usp.br/pluginfile.php/4424269/mod_resource/content/1/como\%20c hegar\%20ao\%20sim.pdf. Acesso em: 03.04.2021.

HERINGER, Mauro Brant. Política Judiciária Nacional. Resolução no 125/2010 do CNJ e a sua efetividade como política pública para redução da judicialização dos conflitos. Rio de Janeiro. 2012. Disponível em http://bibliotecadigital.fgv.br/dspace/bitstream/handle/10438/9791/Mauro\%20Brant\%20He ringer.pdf?seque. Acesso em 27.03.2021.

LIMA, Leonardo Tibo Barbosa. Teoria do conflito Rumo a um novo Direito Coletivo do Trabalho. São Paulo: Ed. LTr, 2016. Disponível em:

http://www.ltr.com.br/loja/folheie/5621.pdf. Acesso em: 27.03.2021.

LEME. Maria Isabel da Silva. Resolução de conflitos interpessoais: interações entre cognição e afetividade na cultura. Disponível em

https://www.scielo.br/scielo.php?script=sci_arttext\&pid=S0102-79722004000300010. Acesso em 01.04.2021.

MATIAS, Maria Judite. Julgados de paz versos centros de arbitragem e estruturas de mediação de consumo: conflito ou convergência? Disponível em:

http://www.conselhodosjulgadosdepaz.com.pt/Intervencoes/JPaz-JulgadosPaz-vs-

CentrosArbitragem.pdf. Acesso em: 05 ago. 2005.

MOTA, Rachel Girão Sobreira. Métodos de tratamento adequados de conflitos no poder judiciário. Disponível em: https://esmec.tjce.jus.br/wpcontent/uploads/2014/12/PDF7.pdf. Acesso em: 05.04.2021. 
RAMIDOFF, Mário Luiz; BORGES, Wilian Roque. Teoria do tribunal multiportas: aplicação da mediação no direito brasileiro. Disponível em:

https://www.tjpr.jus.br/documents/14797/40338175/1.+GA_0009.pdf/001a9233-fa11c83e-ca3a-a58b1e08bec2. Acesso em 05.04.2021.

ROBBINS, Stephen P. Comportamento Organizacional. 11 a ed. São Paulo: Prentice Hall, 2005. Disponível em

https://admdotunisa.files.wordpress.com/2019/03/robbins_2009_livro_comportamento_org aniz.pdf. Acesso em 01.04.2021.

SANTANA, Adriana Oliveira de. Conflitos Interpessoais. Disponível em: https://cdpa.ufg.br/p/29844-conflitos-interpessoais. Acesso em: 01.04.2021.

Semíramis, Maria. 1. Conceito de conflito, $1.1 \mathrm{O}$ que é conflito? Algumas definições. Disponível em http://institutoelo.org.br/site/files/arquivos/d1aaee6d8a529d6737b303af6e4909d6.pdf. Acesso em 05.04.2021).

VASCONCELOS, Mônica Carvalho. Mediação como instrumento de solução deconflitos familiares: a experiência da casa de mediação do Pirambu. Disponível em: http://www.dominiopublico.gov.br/download/teste/arqs/cp079348.pdf. Acesso em: 03.04.2021.

Recebido em: 03/09/2021

Aprovado em: 20/09/2021

Publicado em: 30/09/2021 